\title{
SOME EXPERIENCES IN THE MANAGEMENT OF SUBDURAL HAEMATOMA AND SPONTANEOUS INTRACEREBRAL HAEMORRHAGE
}

\author{
G. B. Northcroft, M.B.E., F.R.C.S. \\ Consultant Neurosurgeon, Regional Neurosurgical Centre, Brook General Hospital, London, S.E. 8
}

My task in this symposium is to review subdural hæmatoma and spontaneous intracerebral hæmorrhage. In my view it would be more profitable to stress the clinical pictures in which surgical intervention is likely to be successful-that is not only saving life but also producing a good functional result-rather than discussing a type of case in which surgical intervention may be disappointing or even futile. During the past 15 years just over 150 cases of subdural hæmatoma have been referred from hospitals in the South East Metropolitan Region and just over half of these have been seen by consultant physicians at these hospitals. It is curious that about the same number of cases of intracerebral hæmorrhage from all causes other than aneurysm has been admitted over the same period. Hæmorrhage associated with angiomatous malformations has been the largest and most interesting group of this number, amounting to just over 60 cases.

Before case examples are chosen to demonstrate the various clinical pictures it may be fruitful to review some of the general principles which have been revealed by the study of both these groups.

Pressure within the cranium, whether the lesion is extracerebral or intracerebral, produces a set series of events. There are only two holes in the box-one at the incisura where the mid-brain lies in the tentorial hiatus and the other at the foramen magnum level where the medulla can be embarrassed by the descent of the cerebellar tonsils.

If a unilateral supratentorial space-occupying lesion exists so-called 'coning' occurs in the first instance at the incisura. The mid-brain may be pushed against the opposite free margin of the tentorium, but it is also pushed down. The

A paper read to a Conference of Physicians of the South East Metropolitan Region at the Brook Hospital, March 17, 1962.

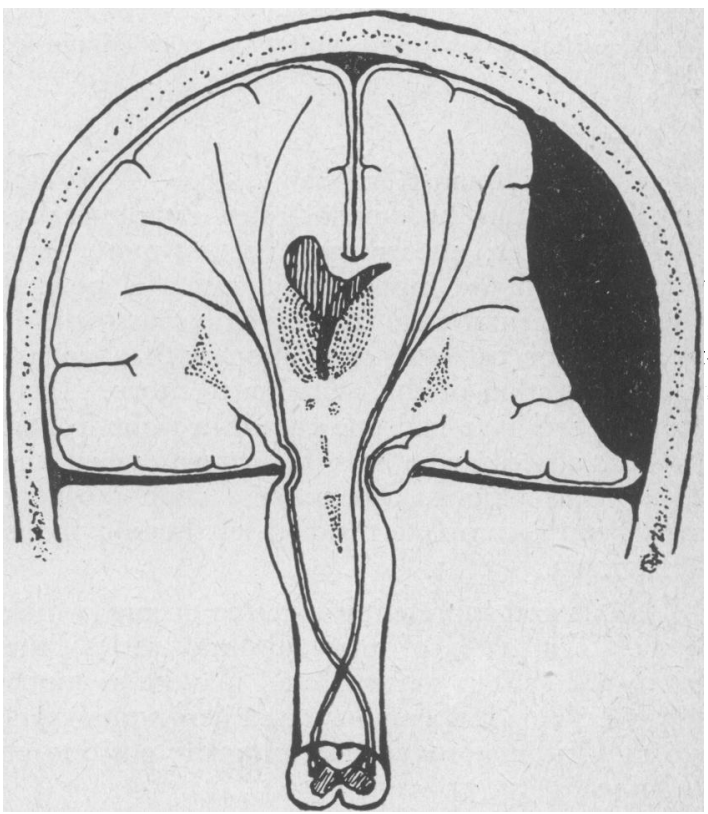

FIG. I.-Shows a subdural hæmatoma with incisural herniation on the left side. The gentle shift may produce ipsilateral signs.

pressure is transmitted to the posterior fossa and so-called 'coning' at foramen magnum level then follows (Fig. I).

Clinically the incisural hernia with the uncus pushed over the anterior tentorial edge often produces ipsilateral pupillary dilatation and contralateral pyramidal signs, usually when the lesion is in the middle fossa. But a gentle non-specific shift due to an effusion over the whole hemisphere may give rise to ipsilateral pyramidal signs as the crus impinges on the opposite tentorial edge. This obtained in $20 \%$ of our cases and is the 


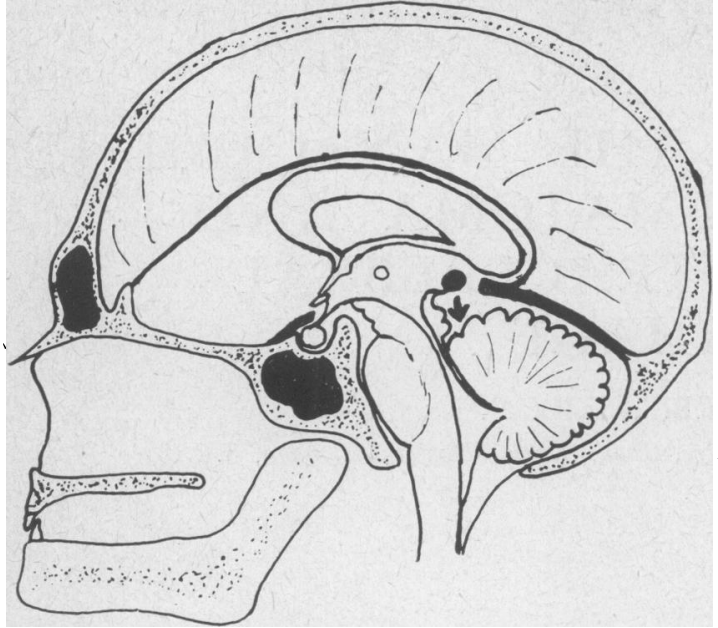

Fig. 2.-Shows downward shift of a calcified pineal.

so-called Woltman/Kernohan sign. A lateral pineal shift may be demonstrated radiologically. Another, rarer, mechanism occurs more posteriorly when the hippocampal gyrus is pushed over the incisural edge causing embarrassment of the posterior cerebral circulation with a consequent infarction of the calcarine territory. Incidentally, we have had one case of a right frontal cerebral abscess who was in extremis when the abscess was tapped. He made a good recovery apart from a complete residual left homonymous hemianopia.

If a bilateral supratentorial lesion occurs (which obtained in $22 \%$ of our subdural series) the downward shift is maximal and may be as much as $2 \mathrm{~cm}$. This was demonstrated here some years ago by Griffiths (1957) measuring the position of the pineal (Fig. 2).

Distortion of the brain-stem vessels produces impairment of the venous return, but the arterial side continues to pump at full pressure into the delicate capillary bed of the pontine vessels. Pathological elevation of the blood pressure occurs in an attempt to overcome this congestion until finally the vessels rupture to produce the classical hæmorrhages. During the stage of congestion when the patient becomes drowsy with sluggish pupils and a slow pulse he is still amenable to surgical aid, but if the full-blown picture of decerebrate rigidity combined with the four Ps, of rapid pulse, fixed pupils, hyperpyrexia and periodic respiration, has occurred the patient has generally developed irreversible brain-stem damage and will not recover even if the exciting space-occupying lesion is removed. Between these two pictures there is an intermediate state in which a rescue may be effected on rare occasions in the nick of time. Indeed, we have seen one case at

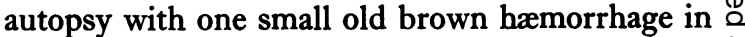
the pons surrounded by clusters of more recent $\subseteq$ hæmorrhages in which the patient had recovered $\overrightarrow{\vec{B}}$ consciousness in the ten days between initial successful drainage and subsequent fatal recurrence.

A further important observation has been the successful use of positive pressure lumbar puncture. On occasions when a chronic subdural hæmatoma has been removed the brain has failed to expand. If the patient has not responded he is turned on his side and a lumbar puncture performed with the burrhole still open. After the $\vec{C}$ injection of between 60 to $100 \mathrm{ml}$. of Ringer's 3 solution there is a sudden give and the brain can $\dot{\omega}_{\infty}$ be seen to come up to the surface. The patient may have become lighter even before the burr hole is closed and it is assumed that the distortion is of the brain stem vessels has been relieved. On $\bullet$ one occasion under these circumstances I asked the theatre sister to pass the tulle-gras to me to put on the wound. The patient responded rather sleepily saying, 'nobody is going to put grass on my head'. This lesson shows that it is dangerous to perform lumbar puncture as a diagnostic aid in this type of case.

The final important point is the assessment of the speed at which the changes just described are occurring. It is well known that a case with an extradural middle meningeal hæmorrhage who has deteriorated about four hours after his injury will be dead by the fifth hour if it has not been relieved. At the other end of the scale a man with a 250-g. meningioma may be alert and his headache may be minimal because of the slow adaptation of the blood/brain/CSF ratios. Most of the cases with intracranial hæmorrhage fall within these two extremes, but the severe bleed in the aged hypertensive patient approximates very closely to the former. In fact these patients are often sent to us from casualty departments because they have fallen in the street and sustained a cut scalp or a skull fracture, but the head injury is secondary to the bleed and not the other way round as often suspected. It is axiomatic that the patient has a much greater chance of being saved if the bleed occurs slowly enough for investigations to be carried out prior to definitive surgical attack.

In the special study of subdural hæmatoma cases it was found that the material presented in two main ways-the first being loosely called the 'coma group' and the second the 'headache group'. 


\section{TABLE I}

Coma group (no lucid interval)

Headache group, comprising: Lucid interval group.. No head injury group
Cases

25

20

In the 'coma group' (25\%) the head injury was severe enough to produce a persistent disturbance of consciousness. There was no lucid interval. At varying times between four hours and 13 days the level of consciousness either fell steadily or fluctuated and finally fell with the development of neurological signs necessitating exploration. Skull fracture was present in $80 \%$, but only crossing the middle meningeal groove on one occasion showing that a subdural rather than an extradural hæmorrhage could be suspected even when the time interval was short.

In the 'headache group' ( $75 \%)$ either the head injury was slight enough to be followed by a lucid interval or no history of head injury was obtainable. In the lucid interval group $(55 \%)$ the time between injury and operation varied between four hours and one year, whereas in the 'no head injury group' (20 cases) the interval between the onset of symptoms and operation varied between ten days and six months. Taking the "headache group' as a whole, headache was followed by deterioration in the level of consciousness with the development of one or more of the following signs in 65 cases-slowing pulse, papillœdema, pupillary change, paresis, extensor plantar response or pineal shift. These signs might be called the 'six Ps' and may, of course, be commonly found in any case with a space-occupying lesion. In seven cases one or more of these signs developed without disturbance of consciousness. Only three cases in the whole series presented without an increase in the neurological signs mentioned above. But atypical cases tend to be remembered although they are only a small percentage of the whole.

The 'no head injury group' is of the greatest interest to the physician. Some authorities say that a subdural effusion cannot occur without a head injury, but this sort of statement is valueless when the physician at the bedside knows that the relevant history is not forthcoming from the patient or even his relatives or friends. An accurate history is probably impossible to obtain in about a third of the cases and the figure is only reduced to a hard core of $20 \%$ when further questioning has occurred after the patient is better.

Regarding the age spectrum in the 'no head injury group', one case was a teenager known to have a hæmorrhagic diathesis, two were over $4^{\circ}$

and the remainder over 50 , the majority falling into the period when the differential diagnosis is most difficult. A search for possible associated diseases was not particularly helpful, but three of the cases were chronic bronchitics and one of them was a patient in this hospital when a bout of coughing initiated persistent headache only relieved by the evacuation of a subdural effusion ten days later. Incidentally, in the past two years we have had three cases in patients on long-term anticoagulants.

A case of outstanding interest was referred by Dr. Staffurth from Lewisham Hospital, a lady of 54 who had undergone laparotomy for an islet cell tumour. Straining at anæsthesia or post-operative coughing may have initiated the subdural effusion which was evacuated a month after the onset of symptoms.

In this group of 20 cases the differential diagnosis was so difficult that angiography was necessary in seven and ventriculography in three before the diagnosis was made. In the ten others the hæmatoma was evacuated fortuitously when ventriculography was indicated but became unnecessary. One most unusual case was sent in with left-sided facial pain and a left ptosis. Angiography revealed a hæmatoma on the right side. From the above experiences it is obvious that the correct diagnosis in this group is just as difficult for us here where we have all the special investigations available.

Time intervals between the head injury and operation or the onset of symptoms and operation for the series:

\section{TABLE 2}

Within 24 hours $\quad$. $\quad 17-10$ deaths, I avoidable. Over 24 hours to 2 weeks $41-1$ I deaths, 9 avoidable. Over 2 weeks .. $\quad$.. 42 -no deaths.

It is seen (Table 2) that no deaths occurred when the history was longer than two weeks, but when the time interval is short the history of a head injury is usually available and therefore the diagnosis should be easier. It is noted that the great majority of cases with no evidence of a head injury occurred in the longest group and therefore came to little harm as a result of possible delay in diagnosis. Only eight cases presented with a history of three months or more and in three of these dementia was a major feature, being referred by psychiatrists. But it should be remembered that even with a known head injury the diagnosis of tumour is at least as likely as subdural hæmatoma at this interval.

The analysis of the occurrence of papillœdema in these cases was of especial interest. It was present in only $17 \%$. Under the age of 20 six out of nine patients had papillodema on admis- 
sion, whereas only two out of 38 over the age of 60 had it. This is rather what one would expect. As we age our brain atrophies and there is more room to contain an effusion within the skull without upsetting the pressures. The cases under 20 were particularly interesting because the three cases which did not have papillœdema were in the 'coma group' and came to operation within three days. In the six cases with papillœdema the interval varied between three and nine weeks. Only two had supratentorial signs, while in the remaining four the hæmatoma was found when ventriculography was performed in investigating a possible posterior fossa tumour.

One of these cases was referred by Dr. Craig from St. Bartholomew's Hospital, Rochester, a boy, aged 7, who had fallen three weeks previously. He had a left sixth nerve palsy and his left pupil was sluggish and he had bilateral papillodema. When ventriculography was intended a ro-ml. subdural hæmatoma was removed on the left and a 60-ml. effusion on the right. He made an excellent recovery.

The lesson we have learnt from these cases is that within a three-day period the patient usually

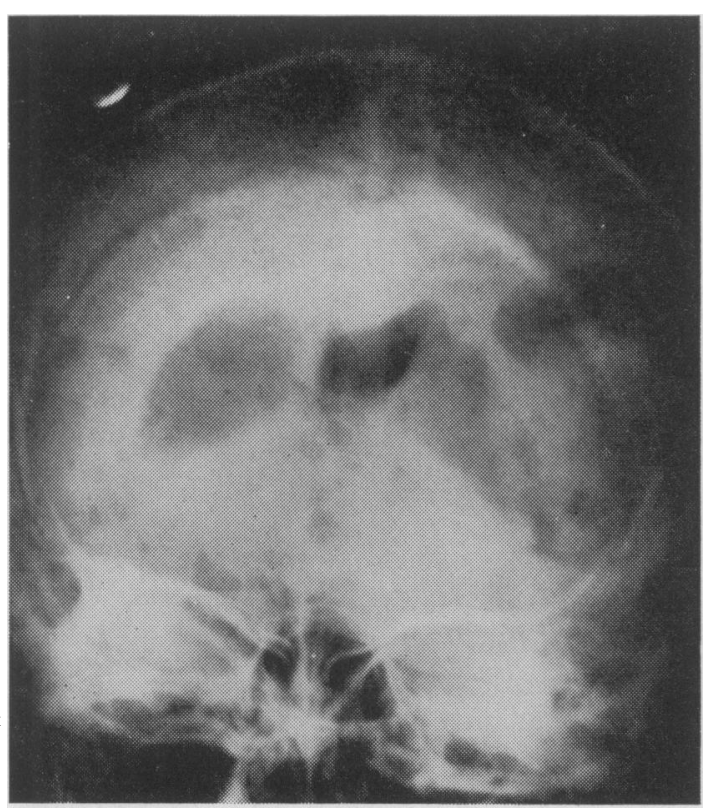

FIG. 3.

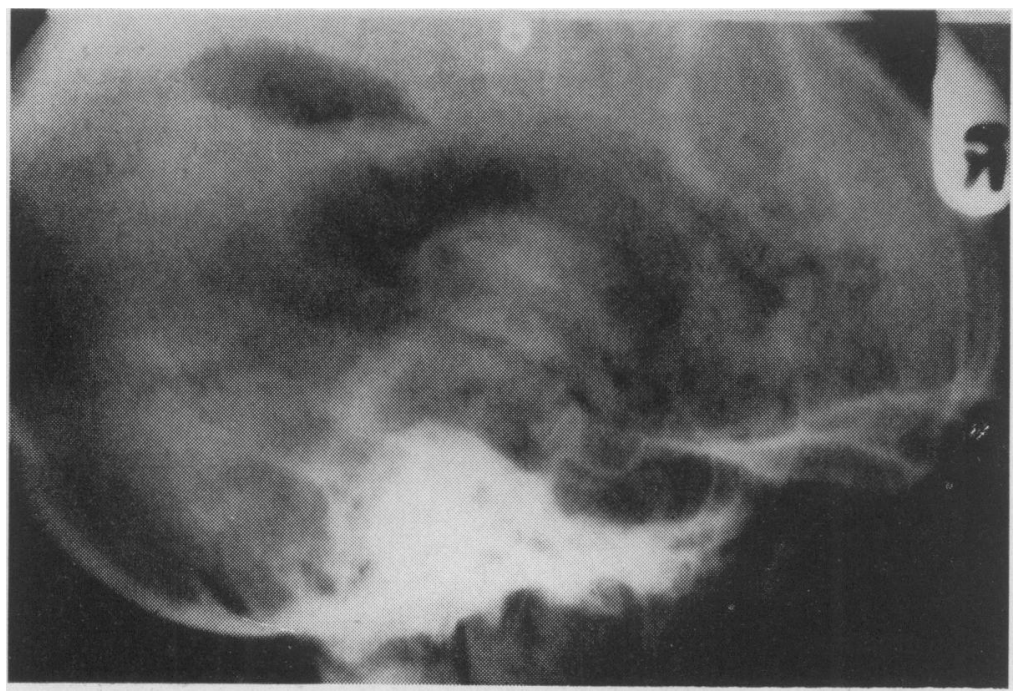

FIGS. 3 and 4.-Show air in a paraventricular cyst after evacuation of blood.

FIG. 4.

goes drowsy or his coma deepens without developing papillodema. Between three weeks and three months he may develop papillœdema before he goes drowsy and after three months he may easily become demented without developing either of these two things. In the cases with a long history symptoms and signs fluctuate, but full remissions do not occur and in this respect they differ from cases of carotid insufficiency.

To sum up then, the old adage that subdural hæmatoma is never found when it is diagnosed and is always found when it is not diagnosed should not obtain today if a history of head injury is forthcoming. It is much more difficult when there is no history of head injury, but subdural hæmatoma can always be borne in mind in the differential diagnosis when a tumour or other trouble in the head is suspected.

The second facet of my task is to review the position regarding surgical intervention when a 


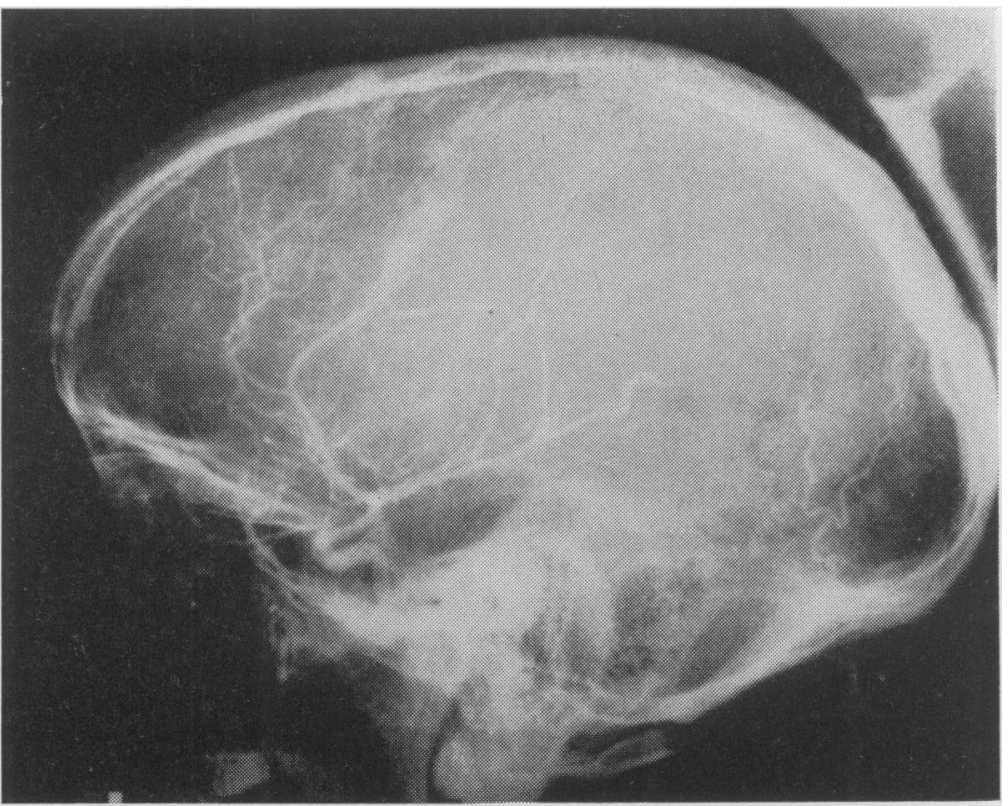

Figs. 5 and 6.-Show an angiomatous malformation on the anterior cerebral artery with an intracerebral clot.

FIG. 5 .

cerebral hæmorrhage occurs in an arteriosclerotic patient who is over the age of 60 with known hypertension.

If deterioration is rapid with early signs of brain stem involvement the outcome is likely to be fatal whatever is done. When death occurs within 24 hours rupture into the ventricle has often taken place. At post-mortem, when the classical lenticulostriate branch of the middle cerebral artery has ruptured, the internal capsule is destroyed and extensive hæmorrhagic softening surrounds it. It is technically possible to resect this hæmorrhagic mass but the patient will survive as a neurological wreck and therefore the exercise is not warranted.

At the other end of the scale disturbance of consciousness may be minimal or transient and neurological signs maximal. A cerebral thrombosis may be diagnosed but a small hæmorrhage may produce an identical picture. Angiography may demonstrate a shift due to swollen brain or clot, but if a clot is present it is not jeopardizing the patient's life and is usually too small to warrant surgical intervention.

Between these two extremes which account for most of the cases there are other possibilities. If slow improvement has occurred over a 24 to 48 hour period further observation is justified because a reasonable neurological recovery occurs in many cases, but it is always disconcerting when occasionally a massive fatal hæmorrhage ensues a few days later after a conservative regime has

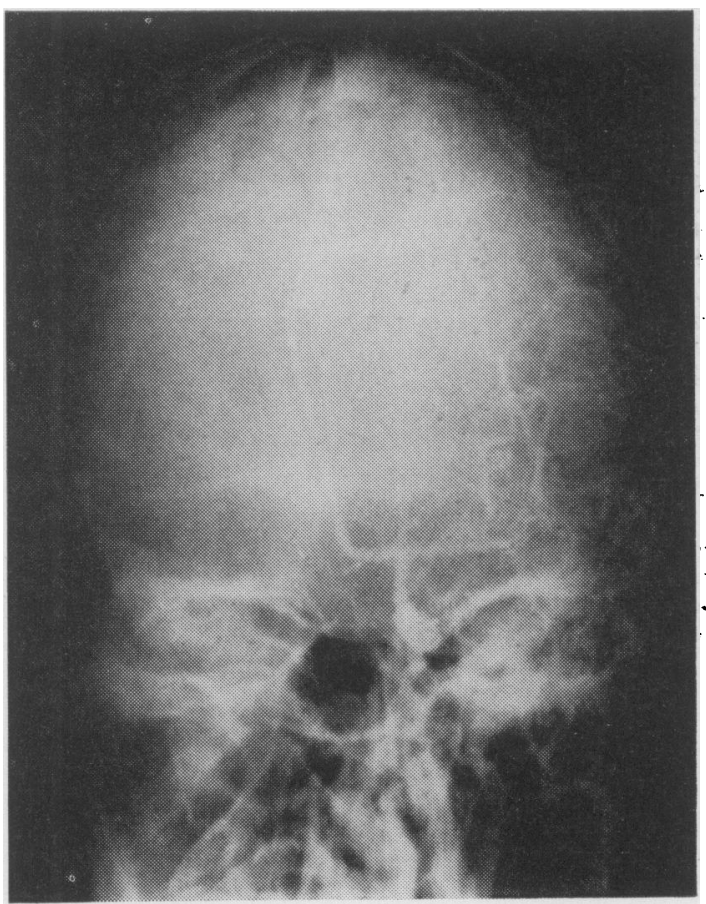

FIG. 6.

been adopted. When deterioration is slow or the patient remains static in semi-coma without brain stem involvement over the 24 to 48 -hour period, 

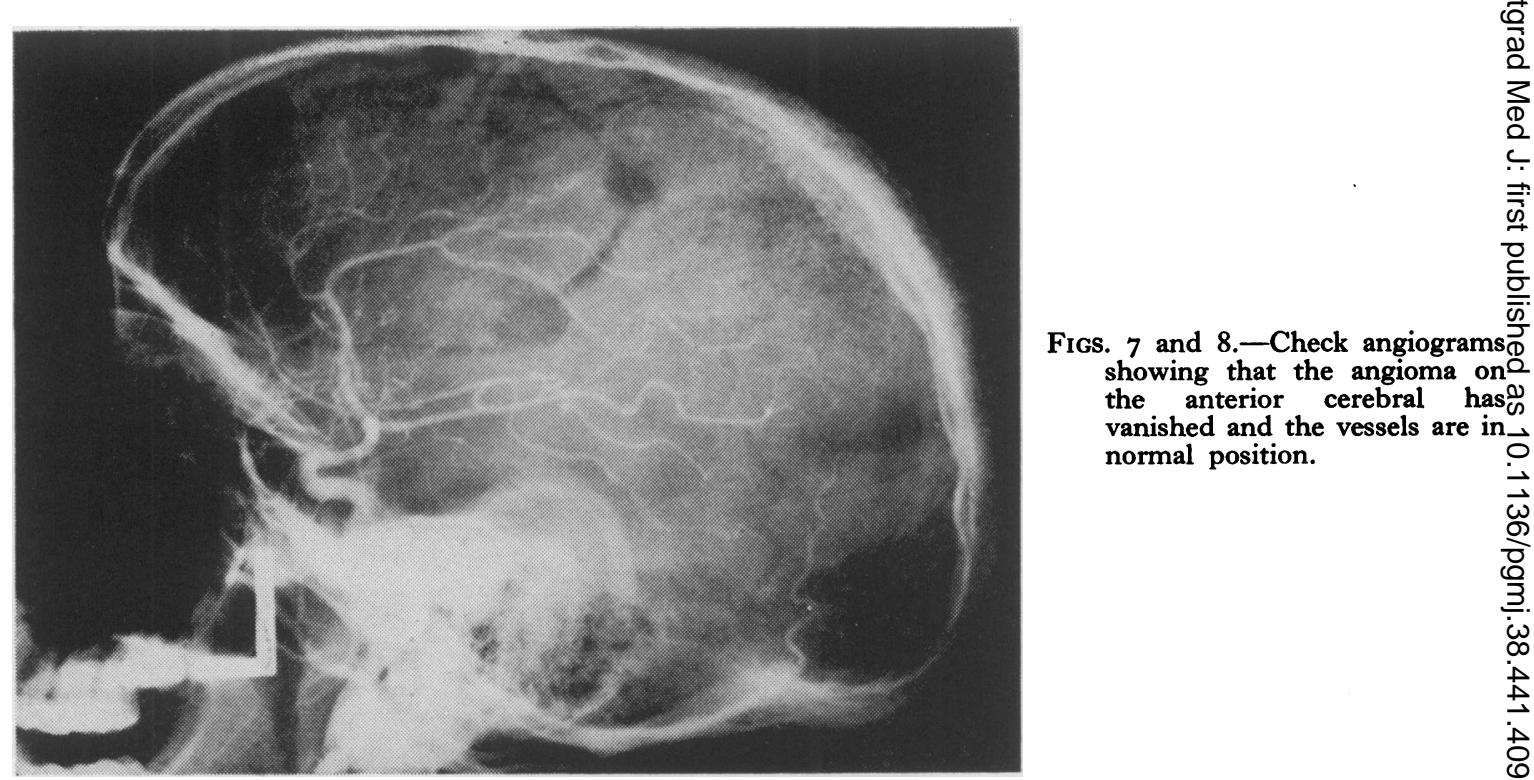

Figs. 7 and 8.-Check angiograms $\widetilde{\widetilde{\Omega}}$ showing that the angioma on $\mathrm{a}$ the anterior cerebral has vanished and the vessels are in normal position.

Fig. 7.

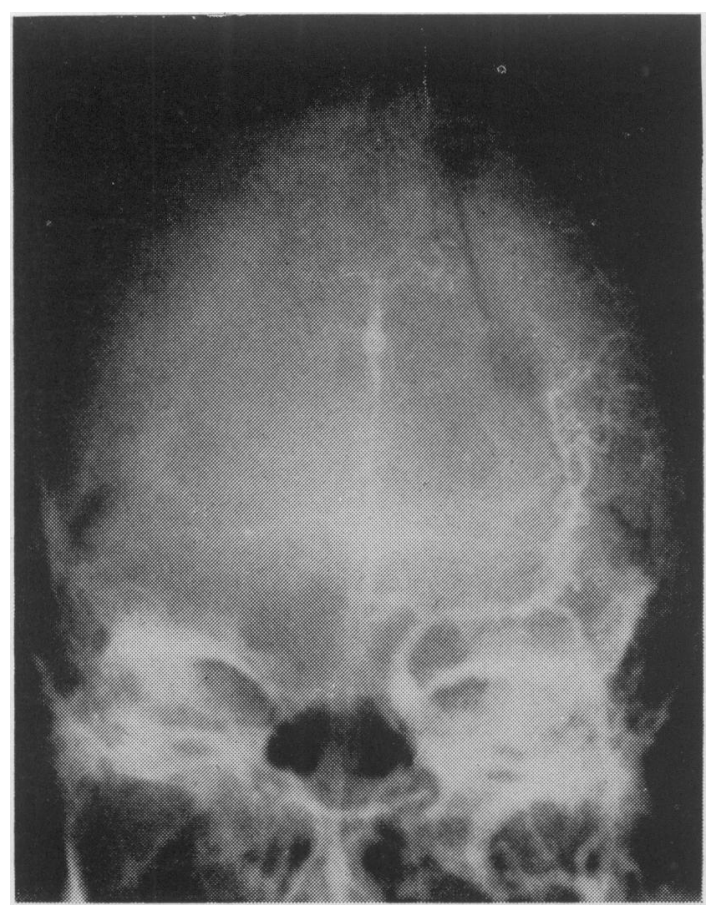

Fig. 8.

surgical intervention preceded by angiography or ventriculography can be contemplated. Sometimes a space-occupying lesion can be demonstrated in a comparatively silent area of the brain

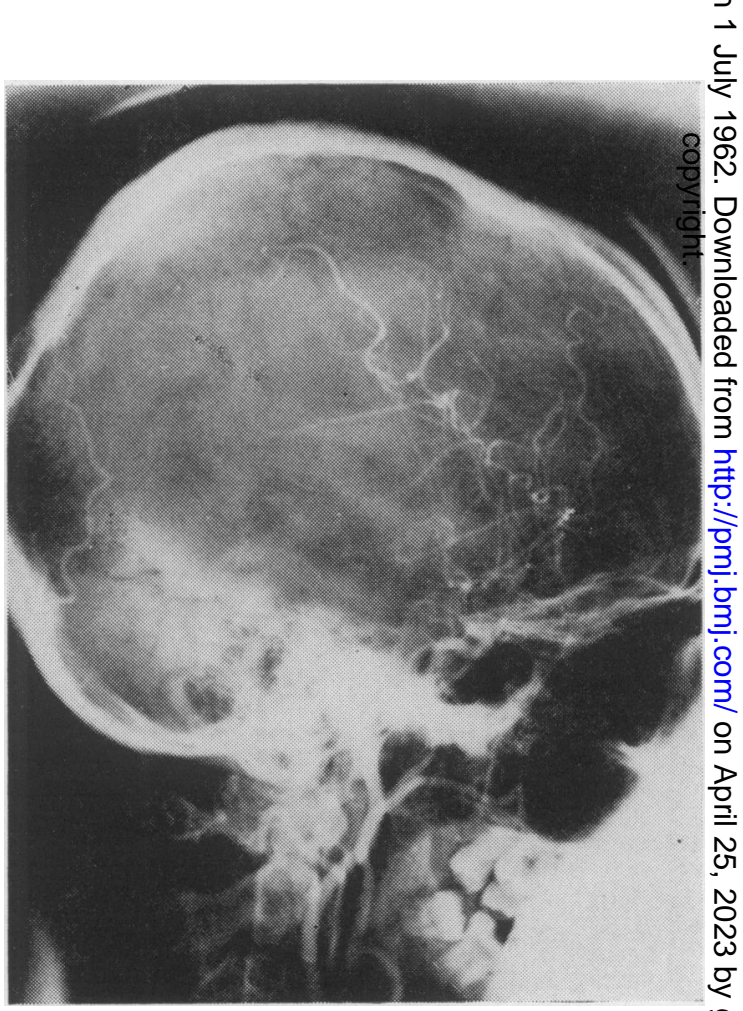

FIG. 9.-Right angiogram showing gross elevation of $\frac{O}{\mathbb{Q}}$ the middle cerebral leash.

rather than in the internal capsule. This is particularly important when a patient is between $\stackrel{\mathbb{D}}{\Omega}$ 40 and 60 and not hypertensive. 


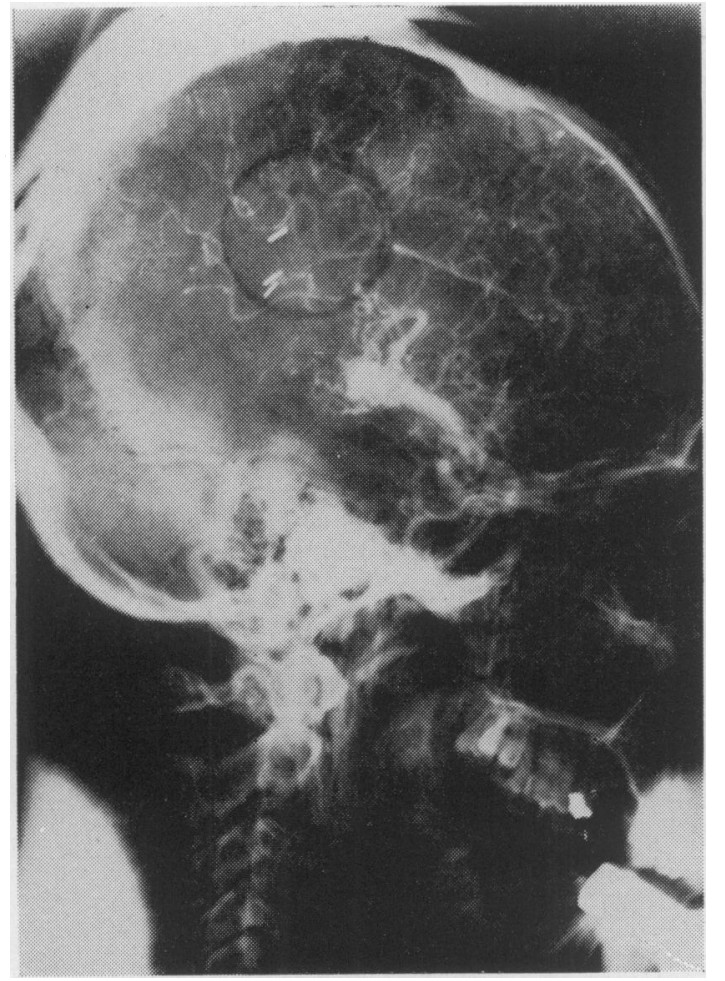

FIG. 10.-Showing rapid serial angiogram of the anterior cerebral. The middle cerebral vessels are now in normal position. The hæmatoma has been totally removed through a trephine disc.

One case (Figs. 3, 4) is typical of several others which have occurred over the years. A man of 66 was referred by his general practitioner with a history of two months' headache and increasing lack of awareness. On the night of admission he went into coma with a right hemiparesis. A subdural hæmatoma was suspected and burr holes made. A ro-ml. subdural effusion was found on the left side and then the brain was seen to pulsate normally. Post-operatively he improved slightly, but remained very drowsy and out of touch with his surroundings. His initial weakness was improving. A fortnight later, when ventriculography was contemplated, a 50-ml. slack cyst was tapped in the position shown. As pressure in the cyst was lowered the ventricle ruptured into it and clear fluid was withdrawn at the end of the tapping. Immediate air studies revealed that the portion of brain destroyed was relatively silent and the man made a slow recovery. Two years later he was living in an old people's home happily making a few extra pennies doing leather work.

The third facet of my task is to cover some of the lessions learnt in treating angiomatous malformations and the cryptic angiomatous hamartomas which have bled. Nearly all cases occurred in normotensive patients under the age of 40 . The term cryptic hamartoma is used when the bleed destroys all underlying radiological and pathological evidence of the malformation.

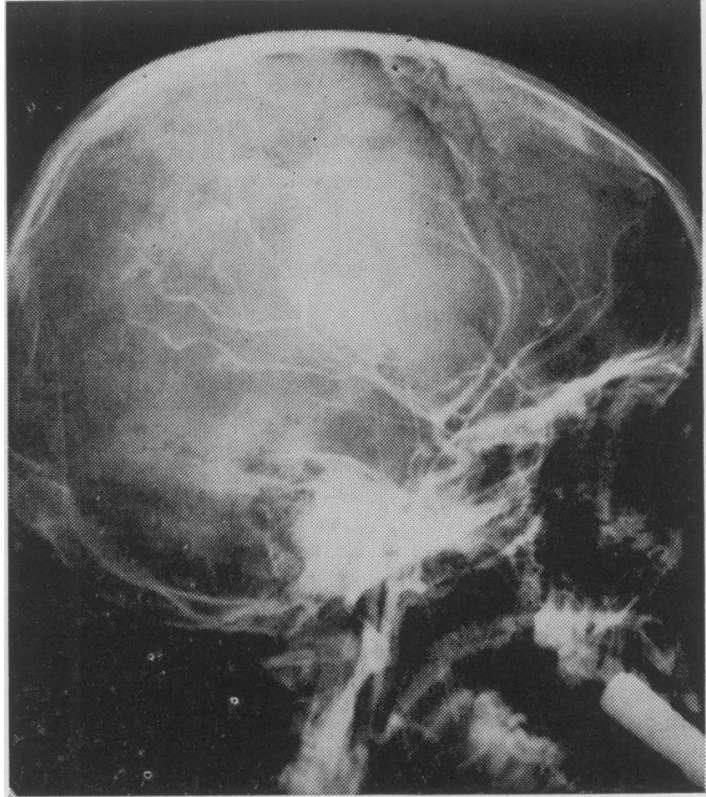

FIG. I I.-Angiogram showing a fine blush due to a capillary angiomatous malformation.

There have been four examples of bleeds from malformations occurring during pregnancy.

One girl, aged 23, was referred by Dr. Michael Price from Lewisham Hospital. She presented with a nine months' history of occasional focal Jacksonian seizures involving the right face. Two months before admission, when she had fallen pregnant, mild frontal headache started. Two weeks before admission this headache started to become really severe. Four days before admission weakness of the right hand appeared. Three days later she had become drowsy, aphasic and had developed a right hemiparesis. When seen by Dr. Price she was recommended for transfer on the same day. Angiography revealed a left frontal space-occupying lesion without a pathological circulation. At craniotomy a $45-\mathrm{ml}$. hæmatoma with a firm capsule was removed. Histology of the capsule showed a typical vascular hamartoma. She did not lose her child and has had a further child in the intervening seven years. In spite of sedation she has had one bad bout of epileptic seizures in 1959, but none since then. A similar case was referred five years ago by Dr. John Glover from Dover, with a very similar result.

Another group of cases is exemplified by a boy of 17 who was batting on a Saturday afternoon when the ball struck his left forehead. He was not knocked out, but later in the day he complained of increasing headache. $\mathrm{He}$ was admitted to Royal Victoria Hospital, Folkestone, under Mr. David Evans, five hours after the injury when he was found to be slightly dysphasic. During the next hour he developed a mild right hemiparesis which then became static. On the Sunday he gradually became less accessible, and on the Monday his pulse rate fell to 55 when he was recommended for transfer.

A left angiogram showed an angiomatous malformation with an intracerebral clot (Figs. 5 and 6). At 
craniotomy later in the day the clot and the malformation was removed.

A check angiography two months later showed that all was well (Figs. 7 and 8). Since then he has been successful in gaining a scholarship in mathematics to Nottingham University, and although he has had several seizures, on sedation he is hopeful of gaining a degree this summer.

Another case demonstrates how the modern technique of rapid serial angiography can be helpful. A boy, aged 24, was admitted to the Kent and Sussex Hospital, Tunbridge Wells, under the care of Dr. King two days after the sudden onset of severe headache while watching television. On admission he was conscious but drowsy, had neck stiffness and a left homonymous hemianopia. A lumbar puncture was performed to exclude a possible subarachnoid hæmorrhage. It revealed a clear fluid under raised pressure, protein $70 \mathrm{mg}$./100 ml., two lymphocytes. On the following day his pulse rate fell to 55 and he developed a mild left hemiparesis and was recommended for transfer.

Right angiography demonstrated a very large spaceoccupying lesion in the posterior part of the hemisphere with elevation of the middle cerebral leash (Fig. 9). At operation, through a trephine disc fluid hromatoma was evacuated followed by the further removal of $30 \mathrm{ml}$. of solid clot. He did well with a complete recovery of his field defect, but while being followed-up he continued to complain of pain behind the right eye. He was readmitted a year later when rapid serial angiography produced this surprise (Fig. 10).
It is probable that this lesion was present all the time and we were unlucky in the first angiography tô get a picture which was out of phase. An osteoplastic flap was turned and the malformation totally removed. $\mathrm{D}$ He returned to full work two months later.

The last case is chosen to illustrate that a patient can ${ }^{C}$ have a space-occupying lesion in the anatomical position of a classical apoplexy and yet make a complete recovery This girl, aged 12, came to us after being seen by Dr.음 Behrman at the Lennard Hospital, Bromley. She hado presented with a mild dysphasia for the past $2 \frac{1}{2}$ years. Increasing clumsiness of the right hand had occurred? in the past $4 \frac{1}{2}$ months and she was admitted as a sus- $\Omega$ pected case of poliomyelitis. While in hospital shen became increasingly drowsy and when Dr. Behrman' found gross papillœedema she was transferred imme- $\overrightarrow{0}$ diately.

Left carotid angiography showed displacement of the $\overrightarrow{\vec{\omega}}$ middle cerebral leash with a fine blush $5 \mathrm{~cm}$. in diameters (Fig. I I ). At craniotomy a well encapsulated subcortical mass containing $35 \mathrm{ml}$. of old blood was totally removed. 3 Histology by Dr. Martin Skelton showed that it was a. capillary angiomatous malformation. A month later hero dysphasia and right hemiparesis had resolved completelyi and since then she has led a perfectly normal life.

In this case the fibres of the internal capsule were; splayed rather than torn up, showing that even the most eloquent area of the brain is amenable to surgical attack, provided these favourable pathological criteria are fulfilled.

I wish to thank the Editor of the British fournal of Radiology for permission to reprint Figure 2.

\section{REFERENCES}

Griffiths, T. (1957): Observations on Cerebral Radiography in a Series of Intracranial Tumours, Brit. F. Radiat 30, 57 . 